\title{
Influence of Adjuvants on Pesticide Soil-Air Partition Coefficients: Laboratory Measurements and Predicted Effects on Volatilization
}

\author{
Supta Das, ${ }^{\dagger}$ Kimberly J. Hageman, ${ }^{{ }^{*}}$ \\ ${ }^{\dagger}$ Department of Chemistry, University of Otago, Dunedin, New Zealand \\ ${ }^{\ddagger}$ Department of Chemistry and Biochemistry, Utah State University, Utah, United States \\ *Corresponding Author: \\ 0300 Old Main Hill, Utah State University, Logan, Utah, USU \\ Fax: $1-435-797-3390$ \\ Telephone: 1-435-797-0114 \\ E-mail: kim.hageman@usu.edu \\ ORCID ID: 0000-0001-9187-5256
}

\begin{abstract}
A solid-phase fugacity meter was used to measure the soil-air partition coefficient values of three semi-volatile pesticides (chlorpyrifos, pyrimethanil, and trifluralin) in the absence of additional adjuvants $\left(K_{\text {soil-air,AI }}\right)$, as part of commercial formulations $\left(K_{\text {soil-air, formulation }}\right)$, and as formulation mixtures with an additional spray adjuvant added ( $\left.K_{\text {soil-air,formulation+spray adjuvant }}\right)$. Chlorpyrifos $K_{\text {soil- }}$ air,formulation values were also measured over $15-30^{\circ} \mathrm{C}$, allowing for the change in internal energy of the phase transfer reaction $\left(\Delta_{\text {soil-air }} U\right)$ to be calculated and compared to the $\Delta_{\text {soil-air }} U$ for $K_{\text {soil-air,AI }}$ from the literature. Finally, measured $K_{\text {soil-air }}$ values were used as input parameters in a pesticide volatilization model to understand how their variability affects pesticide volatilization rates under different conditions. Initial experiments conducted at $\sim 24{ }^{\circ} \mathrm{C}$ indicated that all pesticides volatilized more readily in the presence of adjuvants than in their absence and that the additional spray adjuvant had minimal impact. The $\Delta_{\text {soil-air }} U$ values were 328 and $90 \mathrm{~kJ} / \mathrm{mol}$ for chlorpyrifos in the absence and presence of formulation adjuvants, respectively, suggesting that adjuvants may weaken or disrupt intermolecular attractions between pesticide molecules and soil. At temperatures below $24.5^{\circ} \mathrm{C}$, modelled chlorpyrifos volatilization rates were higher in the presence of adjuvants than their absence; however, the opposite occurred at temperatures above $24.5^{\circ} \mathrm{C}$.
\end{abstract}


Many commonly used pesticides (including insecticides, herbicides, and fungicides) undergo significant volatilization after application, ${ }^{1-4}$ causing a reduction in their intended 38 efficacy. Volatilized pesticides can also undergo atmospheric transport to downwind sites, ${ }^{5-8}$ potentially creating unintended consequences for sensitive non-target organisms. ${ }^{9-12}$ Volatilization rates depend on the strength of the intermolecular interactions between active ingredient (AIs) and the matrices they encounters in the agricultural field. The strength of interactions with soils and 42 plants are best expressed by the AI's soil-air and plant-air partition coefficients ( $K_{\text {soil-air }}$ and $K_{\text {plant- }}$ air, respectively). $K_{\text {soil-air }}$ values can be estimated with a predictive equation, such as the one reported by Davie-Martin et al. that incorporates the AI's octanol-air partition coefficient ( $\left.K_{\text {octanol-air }}\right)$ as well as temperature, relative humidity $(\mathrm{RH})$, and the soil's fraction of organic matter. ${ }^{13}$ Predictive

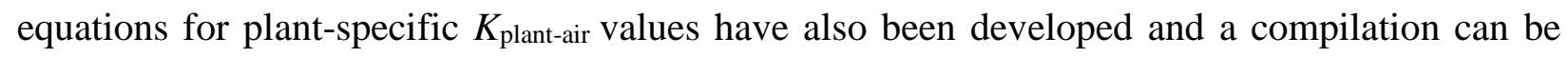

47 found in Taylor et al. ${ }^{14}$ The Pesticide Loss via Volatilization (PLoVo) model uses these partition coefficients to predict AI volatilization under different scenarios. ${ }^{14}$

While $K_{\text {soil-air }}$ and $K_{\text {plant-air }}$ values, and the predictive equations developed from them, provide quantitative information about AI interactions with soil and plants, these values do not take into

51 account the effects that other chemicals applied with AIs may have on these interactions. This is 52 an important consideration because pesticide AIs are generally applied to agricultural fields as components of formulations that contain a number of chemicals other than the AI and the main

54 solvent; these additional chemicals are called adjuvants. Formulation adjuvants are premixed with 55 AIs before sale whereas spray adjuvants (also called tank-mix adjuvants) are separate products 56 that are added to the spray tank by the applicator. ${ }^{15}$ Common adjuvants include surfactants, 57 compatibility agents, antifoaming agents, and spray colorants (dyes) (Supporting Information (SI) 
58 Table S1). Among other things, adjuvants may be used to improve mixing, application 59 effectiveness, ease-of-use, or pesticide activity and they may be used to reduce spray drift, 60 foaming, or buffer the $\mathrm{pH}$.

61 Several studies have investigated the effects of adjuvants on pesticide volatilization rates 62 from surfaces. Most such studies were conducted with pesticides applied to glass surfaces or filter 63 paper; the results of five such studies are summarized in Table S2. In some cases, adjuvants led to 64 reduced AI volatilization from these surfaces, but in other cases, the opposite occurred. ${ }^{2,16}$ Stevens 65 and Bukovac reported a 3-6 times increase in atrazine volatilization from polytetrafluoroethylene 66 (PTFE) disks in the presence of adjuvants but the same set of adjuvants caused a 45-70\% decrease 67 in DDT volatilization. ${ }^{17}$ Houbraken et al. measured the effects of several adjuvant types on the 68 volatilization of three AIs from glass surfaces and showed that the effects varied widely depending 69 on the adjuvant-AI combination. ${ }^{2,18}$ To the best of our knowledge, only one previous study 70 investigated the effects of adjuvants on pesticide volatilization from soil and in that case, atrazine 71 volatilization was not significantly affected by the adjuvants in an emulsifiable concentrate. ${ }^{19}$ An 72 approach for measuring 'effective vapor pressures' of AIs in the presence of adjuvants has been 73 developed and Houbraken et al. suggested that these values be used in chemical fate models in 74 place of saturated vapor pressures. ${ }^{2}$

75 The advantage of conducting pesticide volatilization studies on glass or PTFE disks is that 76 the adjuvant effects can be measured with minimal complicating factors; however, it is unlikely 77 that such results fully predict pesticide behavior on soil or plant surfaces. Likewise, effective vapor 78 pressures do not necessarily indicate how adjuvants effect the intermolecular interactions that bind 79 AIs to soil or plant surfaces. This is particularly important considering previous work showing that 80 multiphase partitioning better predicts AI volatilization than vapor pressure. ${ }^{20}$ Additionally, there 
81 are no reports about temperature effects on pesticide volatilization in the presence of adjuvants;

82 this is an important consideration in light of the significant effect that temperature has on

83 volatilization rates. Thus, huge gaps in knowledge still exist in this research area.

84 The first objective of this study was to measure and compare the $K_{\text {soil-air }}$ values of three

85 pesticides in the absence of adjuvants $\left(K_{\text {soil-air,AI }}\right)$, in their common commercial formulations $\left(K_{\text {soil- }}\right.$

86 air,formulation values), and in the commercial formulations containing an additional spray adjuvant

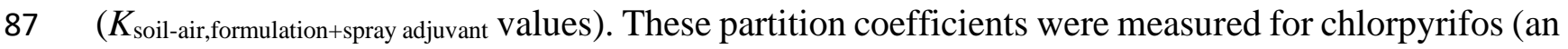

88 insecticide), pyrimethanil (a fungicide), and an herbicide (trifluralin). The second objective was to

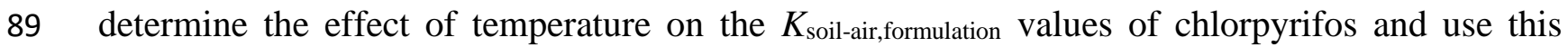

90 information to better understand the mechanism underlying adjuvant effects. The third objective

91 was to determine how pesticide volatilization, as predicted by the PLoVo model, varies when $K_{\text {soil- }}$

92 air values measured in the presence and absence of adjuvants were used as input parameters in the

93 model. Partition coefficients were measured with a solid-phase fugacity meter and two designs

94 were compared.

95

96 MATERIALS \& METHODS

97 Chemicals.

98 Chlorpyrifos analytical standard was purchased from Fluka (Steinheim, Germany), 99 pyrimethanil from Sigma Aldrich (St. Louis, MO), and trifluralin from Supelco (Bellefonte, PA). 100 High-purity dichloromethane (>99.98\%), ethyl acetate (>99.9\%), $n$-hexane (>98\%), and acetone 101 (>99.98\%) were obtained from Merck (Darmstadt, Germany). Isotopically labelled chlorpyrifos$102 \mathrm{~d}_{10}$ was acquired from Cambridge Isotope Laboratories (Andover MA), pyrimethanil- $\mathrm{d}_{5}$ from 
Sigma-Aldrich (St Louis, MO), and trifluralin-d ${ }_{14}$ from CDN Isotopes (Pointe-Claire, Quebec, Canada).

Commercial formulations and the spray adjuvant, all of which are currently registered for use in New Zealand, were purchased from a local farm store. The commercial formulations were Chlor-P-480EC (containing 48\% of the insecticide AI, chlorpyrifos), Pyrus ${ }^{\circledR} \mathrm{SC}$ (containing 38$41 \%$ of the fungicide, pyrimethanil) and Trifluralin 480 EC (containing $48 \%$ of the herbicide, trifluralin). The spray adjuvant was Synoil ${ }^{\mathrm{TM}}$, which contains $>60 \%$ mineral oil, with the

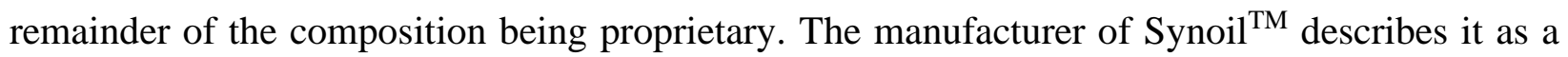
proprietary blend of paraffinic and polyol fatty acid esters for use with herbicides, insecticides, and fungicides that enhances spreading, wetting, and sticking and acts as an anti-evaporant. ${ }^{21}$ Additional details about each formulation, including available information about other mixture components, and the spray adjuvant are provided in Table S3.

\section{Soil Preparation.}

Semi-arid soil was obtained from AgResearch at the Invermay Campus in Mosgiel, New Zealand. The organic carbon content $\left(f_{\text {oc }}\right)$ of the soil was $2.81 \%$ and the sand, silt and clay contents of the soil were $21 \%, 60 \%$ and $19 \%$, respectively. It had a particle density of $2.59 \mathrm{~g} \mathrm{~cm}^{-3}$ and $\mathrm{pH}$ of 5.6 (Table S4). A detailed description of the soil characterization approach is given in SI Section I. The soil was sieved to $<1-\mathrm{mm}$ diameter particle size and dried by baking overnight at $110^{\circ} \mathrm{C}$ so that the initial soil moisture content was equivalent for all experiments. This soil was then divided into two portions; one portion was used with Column Design experiments and was contaminated by adding a solution containing the three AIs in hexane and allowing the hexane to completely evaporate in a rotary evaporator using the previously described procedure. ${ }^{13}$ The other 
126 portion of soil was stored in a sealed glass jar at $-20{ }^{\circ} \mathrm{C}$ and used with the Flat Pan Design 127 experiments.

Measurement of $K_{\text {soil-air Values. }}$

A solid-phase fugacity meter, based on the design originally described by Horstmann and

McLachlan, ${ }^{22}$ was used to measure pesticide $K_{\text {soil-air,AI }}, K_{\text {soil-air,formulation, }} K_{\text {soil-air,formulation+spray adjuvant }}$ 132 values. All experiments were conducted in triplicate. Initially, two fugacity meter designs 133 employing different types of soil compartments (the Column Design and the Flat Pan Design), 134 were compared; details about the two designs are in the next section. In both systems, nitrogen 135 (used as a proxy for air) from a compressed tank flowed through a humidity controller (Roscid 136 Technologies, MA, USA), a soil container (column or pan), a sorbent trap, and finally through a 137 gas flow meter (capable of measuring 0.0-0.5 $\mathrm{L} \mathrm{min}^{-1}$; Parkinson Cowan Industrial Products, 138 England) for $\sim 24 \mathrm{~h}$ at a flow rate of $\sim 0.1 \mathrm{~L} \mathrm{~min}^{-1}$ (Figure S1 and Figure S2). This flow rate was 139 used because previous experiments conducted with the Column Design indicated that pesticide 140 equilibrium between soil and air was established at this flow rate. ${ }^{13}$ The $\mathrm{RH}$ of the nitrogen flowing 141 through the system was maintained at $75 \%$ to ensure constant moisture content in the soil. While 142 moisture has a significant effect on pesticide volatility, we did not vary it since the effects of RH 143 on pesticide volatilization have been investigated in previous studies ${ }^{23,24}$ The soil container and sorbent trap were housed in a temperature-controlled chamber. The 145 sorbent trap was a 34-mL Accelerated Solvent Extractor (ASE) cell body containing 12 g XAD-2 146 sorbent (Restek, Australia) and 30-mm glass fiber filters (GFFs) (Restek, Australia) at each end. 147 When experiments were completed, AI concentrations were measured in the XAD-2 sorbent and 148 soil samples. Gas-phase pesticide concentrations were determined by dividing the pesticide mass 
149 in the XAD-2 sorbent by the total volume of nitrogen that had passed through the fugacity meter. Additional details about the experimental procedure and validation are provided in SI Section II.

152 Comparison of Fugacity Meter Designs

The Column Design (Figure S2 (a)) employed a glass column containing pesticide-

154 contaminated soil whereas the Flat Pan Design (Figure S2 (b \& c)) employed a glass pan 155 containing soil onto which an aqueous pesticide solution was applied. We compared $K_{\text {soil-air,AI }}$ 156 values measured with these designs because the Column Design was used in previously described 157 experiments; ${ }^{13}$ however, the Flat Pan Design better represents a field scenario in which pesticides are applied to a soil surface over which air flows. We hypothesized that the designs would produce 159 different $K_{\text {soil-air }}$ values, with those from the Flat Pan Design being more relevant for predicting pesticide volatilization from agricultural soils.

Details about the Column Design set-up are provided elsewhere. ${ }^{13}$ Briefly, the glass column contained 200-500 g of dry pesticide-contaminated soil through which nitrogen flowed. At the end of the experiment, the XAD-2 sorbent trap was removed and the contaminated soil was moved from the glass column to a glass jar where it was mixed thoroughly before removing three aliquots for analysis $(1.1 \mathrm{~g}$ each).

When using the Glass Pan Design, 250-400 $\mathrm{g}$ of dry soil ( 1 $\mathrm{cm}$ depth) was placed in a 167 glass pan $(34-\mathrm{cm}$ length $\times 24-\mathrm{cm}$ width $\times 5$-cm depth $)$ at the start of each experiment. For these 168 experiments, $0.5 \mathrm{~mL}$ of a solution containing $10 \mathrm{~g} \mathrm{~L}^{-1}$ of all three AIs in distilled water (prepared 169 from solid analytical standards) was applied uniformly across the soil surface with a microsyringe, 170 resulting in $5 \mathrm{mg}$ of each AI being applied to the soil ( $\sim 50$ droplets of $\sim 0.1 \mathrm{~mL}$ each). This resulted 171 in an AI application rate in the baking tray of $63 \mathrm{mg} \mathrm{m}^{-2}$ or $630 \mathrm{~g} \mathrm{ha}^{-1}$, which is similar to those 
172 recommended by the manufacturers for field applications (Table S5). A flat glass lid was then

173 sealed onto the pan with a thin strip of silicone; the lid contained inlet and outlet ports for nitrogen

174 flow. After pesticide application, the pan was immediately placed in the temperature-controlled

175 chamber and nitrogen flow was established. At the end of the experiment, the XAD-2 sorbent trap

176 was removed and three soil samples were collected from random locations in the pan by placing a

177 copper ring $(19.6-\mathrm{cm}$ diameter $\times 3-\mathrm{cm}$ height $)$ on the soil surface and removing the soil $(\sim 10 \mathrm{~g})$

178 within the ring's area. The soil from the three locations was mixed thoroughly in a glass jar and

179 three aliquots (1.1 g each) were removed for analysis.

In sum, several differences between Column Design and Flat Pan Design existed. First, pesticides several weeks earlier to allow for an 'aged sorption' effect and thus stronger pesticidesoil binding, a topic discussed in several previous publications. ${ }^{25,26}$ In contrast, time for an ageing effect was not incorporated into the Flat Pan Design experiments. Third, the soil used in the Column Design was contaminated with pesticides by applying a pesticide solution in hexane to the soil and fully evaporating the hexane. In contrast, pesticides applied to soil in the Flat Pan Design were applied as aqueous solutions. With regards to this last point, however, the volume of water $(\sim 0.5 \mathrm{~mL})$ applied to the soil in the pan $(\sim 250-400 \mathrm{~g})$ was small relative to the amount of soil and we suspect that it sorbed into soil without significantly affecting pesticide AI behavior.

\section{Quantifying the Effect of Adjuvants and Temperature on Soil-Air Partitioning}

All experiments designed to assess the effects of adjuvants and temperature on soil-air partitioning was conducted in triplicate. For the measurement of $K_{\text {soil-air,formulation values, separate }}$ 
195 solutions were prepared from each of the three purchased formulations. Formulations were diluted

196 in distilled water such that the AI concentrations $\left(10 \mathrm{~g} \mathrm{~L}^{-1}\right)$ were identical to those used for the

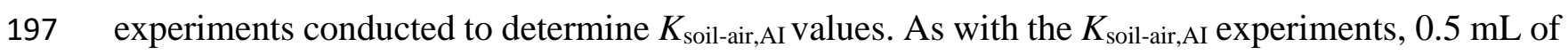

198 the solution was applied to the baking pan, resulting in $5 \mathrm{mg}$ of AI applied to the pan. For the

199 measurement of $K_{\text {soil-air,formulation+spray adjuvant values, spray adjuvant was included in the diluted }}$

200 formulation solutions such that its concentration was $10 \mu \mathrm{L}$ of Synoil ${ }^{\mathrm{TM}}$ per $\mathrm{mL}$ of solution. This

201 resulted in a Synoil ${ }^{\mathrm{TM}}$ application rate in the baking tray of $0.063 \mathrm{~mL} \mathrm{~m}^{-2}$ or $630 \mathrm{~mL} \mathrm{ha}^{-1}$, which is

202 similar to that recommended by the manufacturer for field applications. Each formulation and

203 formulation/adjuvant combination was tested in separate experiments. Otherwise, these

204 experiments were conducted in an identical manner to those described above for the determination

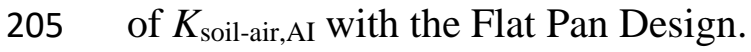

206 The effect of temperature on the soil-air partitioning of chlorpyrifos in the presence of

207 formulation adjuvants was determined by measuring chlorpyrifos $K_{\text {soil-air,formulation values at four }}$

208 temperatures $\left(\sim 15, \sim 20, \sim 24\right.$, and $\left.\sim 30^{\circ} \mathrm{C}\right)$. Table S6 summarizes all experiments conducted with

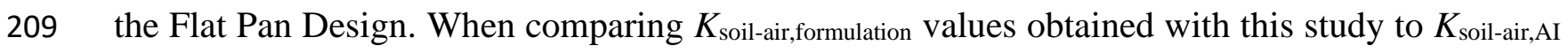

210 values reported previously, partition coefficients from both studies were normalized to $1 \% f_{\text {oc }}$ by

211 dividing $K_{\text {soil-air }}$ values by the $f_{\text {oc }}$ of the soils used and multiplying by 0.01 .

212

213 Pesticide Extraction, Quantification, and Quality Control

Pesticide extraction and quantification methods are described in detail in SI Section III.

215 Quality control procedures are described in SI Section IV.

216

217 


\section{Statistical Analysis}

Welch t-tests (assuming unequal variance, $\alpha$ of 0.05 ) were conducted with Microsoft Excel 2010 to compare the means of pesticide $K_{\text {soil-air,AI values obtained with the Column Design and Flat }}$ Pan Design and to compare the means of $K_{\text {soil-air,AI, }} K_{\text {soil-air,formulation, }} K_{\text {soil-air,formulation+spray adjuvant }}$ for each AI.

\section{Predicting the Effects of Adjuvants on Pesticide Volatilization Rates}

We used the PLoVo model ${ }^{14}$ to predict the cumulative percent volatilization during the $24 \mathrm{~h}$ after application $\left(\mathrm{CPV}_{24 \mathrm{~h}}\right)$ of each $\mathrm{AI}$ from a model agricultural field containing no plants by using

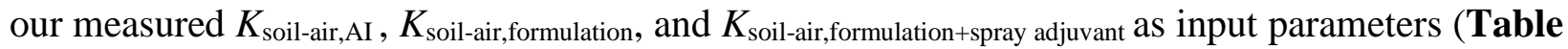
S9). All of the measured soil-air partition coefficients used in the modeling were obtained from the Flat Pan Design experiments. We also compared $\mathrm{CPV}_{24 \mathrm{~h}}$ values for chlorpyrifos along a temperature trend by using our measured $K_{\text {soil-air,formulation }}$ values at various temperatures and $K_{\text {soil- }}$ air,AI values obtained from the literature for the same temperature range. The pesticide properties used in the model are in Table S10 and other key input parameters are in Table S11. Although trifluralin is often mixed into the soil during its application, the predicted $\mathrm{CPV}_{24 \mathrm{~h}}$ values reported here represent a situation in which it is applied to the soil surface.

\section{RESULTS AND DISCUSSION}

\section{Influence of Chamber Design on Soil-air Partitioning.}

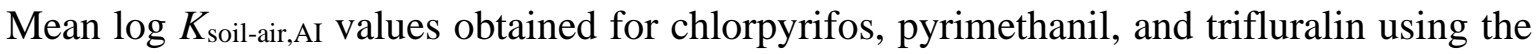
two fugacity meter designs were compared using experiments conducted at $\sim 24{ }^{\circ} \mathrm{C}$ and $\sim 75 \% \mathrm{RH}$

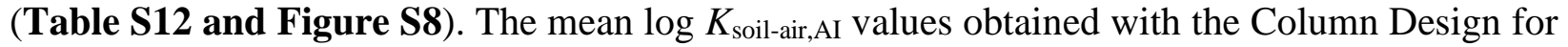


241 chlorpyrifos, pyrimethanil, and trifluralin were 8.3, 7.9, and 7.4, respectively, while those obtained

242 with the Flat Pan Design were 8.1, 8.9, and 7.1, respectively. Thus, the mean values obtained with

243 the two designs were not significantly different for chlorpyrifos $(p=0.6)$ or trifluralin $(p=0.1)$

244 but the value for pyrimethanil was around one log unit higher and significantly different $(p=0.003)$

245 when using the Flat Pan Design compared to the Column Design (Table S13).

246 Results from a number of studies suggest a strong correlation between $K_{\text {octanol-air }}$ and $K_{\text {soil- }}$

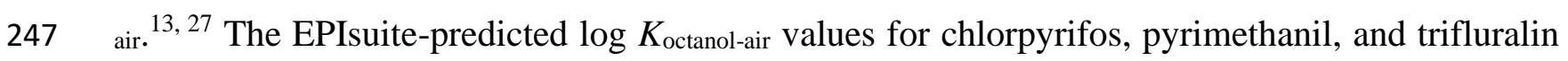

248 at $25{ }^{\circ} \mathrm{C}$ are $8.9,8.7$, and 7.7 , respectively (Table S10). ${ }^{28}$ Thus, the values obtained with the

249 Column Design are better correlated with $\log K_{\text {octanol-air }}$ than those obtained with the Flat Pan

250 Design. This could suggest an error in our measured $K_{\text {soil-air,AI }}$ of pyrimethanil with the Flat Pan

251 Design even though reproducibility was exceptionally good (Figure S8). However, it is also

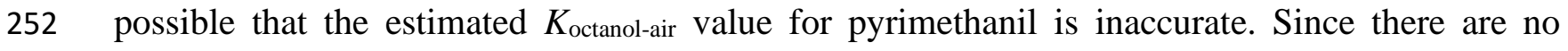

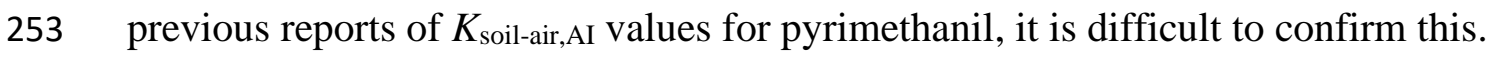

254 Regarding our hypothesis concerning fugacity meter design, we expected the Flat Pan

255 Design to produce partition coefficients representing pesticide interactions with the soil surface

256 layer and therefore to be more representative of actual field conditions than the Column Design.

257 However, since the design impacted the results for one pesticide but not the other two, the potential

258 effect of fugacity meter design was not conclusive. It is also worth noting that the $K_{\text {soil-air,AI value }}$

259 for pyrimethanil was higher when using the Flat Pan Design; this suggests that the proposed 'aged

260 sorption' effect for soils used with Column Design experiments was not significant. In other words,

261 there was no evidence that incorporating the pesticide into soil and allowing a 'rest period' of a

262 few weeks led to tighter pesticide-soil interactions because that would have resulted in

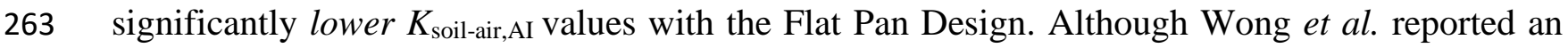


264 aged sorption effect for organochlorine pesticides and polychlorinated biphenyls and suggested 265 that spiked chemicals become increasingly tightly bound to the soil over time, ${ }^{29}$ Cousins et al. 266 reported no aging effect on the soil-air partitioning of polychlorinated biphenyls. ${ }^{25}$ Similarly, 267 Sharer et al. reported no difference in sorption in one day and 30-day aged atrazine in soil. ${ }^{26}$

268 Effect of Adjuvants on Soil-Air Partition Coefficients.

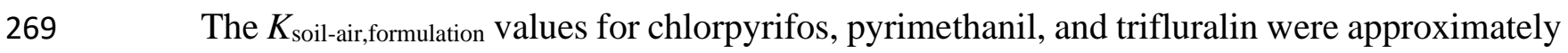
270 an order of magnitude lower and significantly different than their corresponding $K_{\text {soil-air,AI values }}$ 271 ( $p=0.07,0.0001,0.006$, respectively) when measured at $\sim 24{ }^{\circ} \mathrm{C}$ and $\sim 75 \% \mathrm{RH}$ (Figure 1, Table 272 S14). These results suggest that these active ingredients were more volatile when applied in the 273 selected formulations (Table S1) than when applied in an aqueous solution not containing 274 adjuvants under these conditions. On the other hand, the addition of the spray adjuvant, Synoil, ${ }^{\mathrm{TM}}$ 275 to the tested formulations, had minimal additional effect on partitioning (Figure 1). 


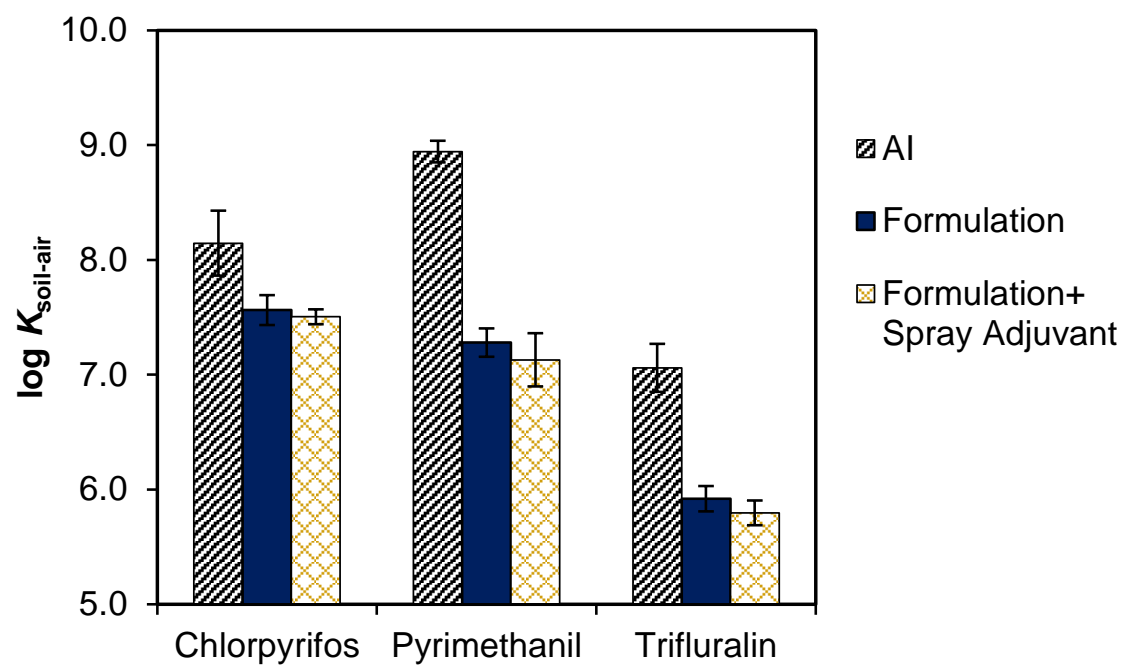

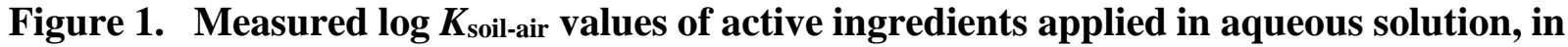
a commercial formulation, and in a commercial formulation with Synoil ${ }^{\mathrm{TM}}$ added as a spray adjuvant. Experiments were conducted at $\sim 24{ }^{\circ} \mathrm{C}$ and $\sim 75 \%$ RH. Error bars represent one standard deviation $(n=3)$.

277 between pesticide active ingredients, adjuvants, and the soil matrix. ${ }^{30,31}$ Thus, at this point, we

278 hypothesized that the active ingredients we tested underwent more volatilization when applied as

279 a formulation because the adjuvants disrupted or weakened the intermolecular interactions

280 between the active ingredient and the soil molecules (Figure 2). For example, because of its lone

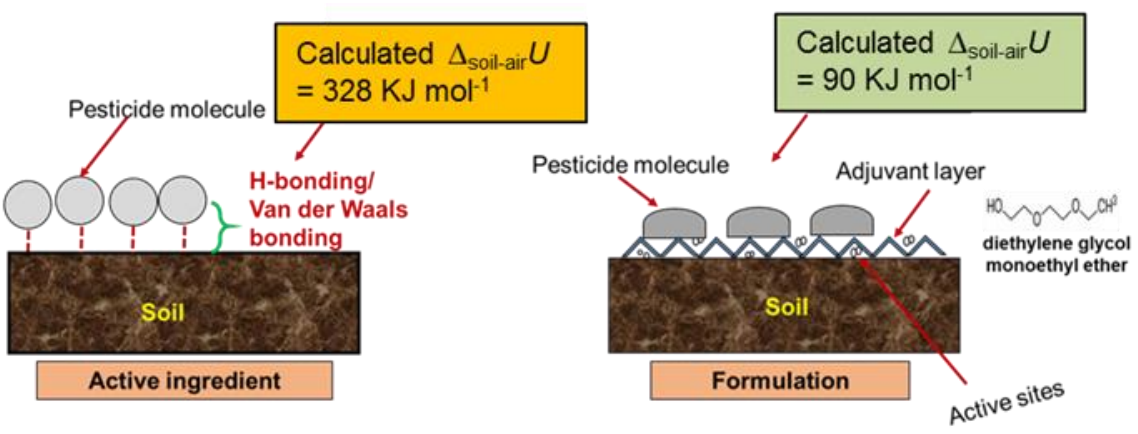

Figure 2. Simplified depiction of proposed mechanism for disruption of pesticide-soil intermolecular attractive bonds by adjuvants, explaining our observation that

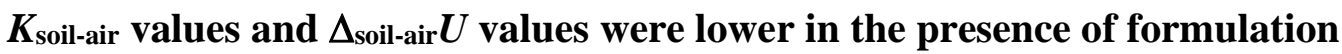
adjuvants. 
281 electron pairs, the diethylene glycol present in the chlorpyrifos formulation would likely

282 outcompete chlorpyrifos for soil binding sites, leading to increased chlorpyrifos volatilization.

283 The formulations we employed were emulsifiable concentrates in the cases of chlorpyrifos 284 and trifluralin and a suspension concentrate in the case of pyrimethanil (Table S3). While the 285 complete chemical compositions of the formulations we used in this study are not publicly 286 available, emulsifiable concentrates often include solvents and co-solvents (Table S1). ${ }^{32}$ 287 Houbraken et al. reported that the volatility of fenpropimorph and pyrimethanil from glass slides 288 was strongly affected by solvent type. ${ }^{2}$ For example, they found that pesticide volatility was not 289 affected by the presence of a relatively high volatility solvent (dichloromethane) in formulations, 290 but that the volatilization of pyrimethanil and fenpropimorph from glass slides was reduced by $29179 \%$ and $53 \%$, respectively, in the presence of a relatively low volatility solvent (Solvesso $^{\mathrm{TM}}$ 292 200ND). Their explanation was that highly volatile solvents evaporate from surfaces before they 293 can affect pesticide AI behavior whereas lower volatility solvents remain on surfaces and trap the 


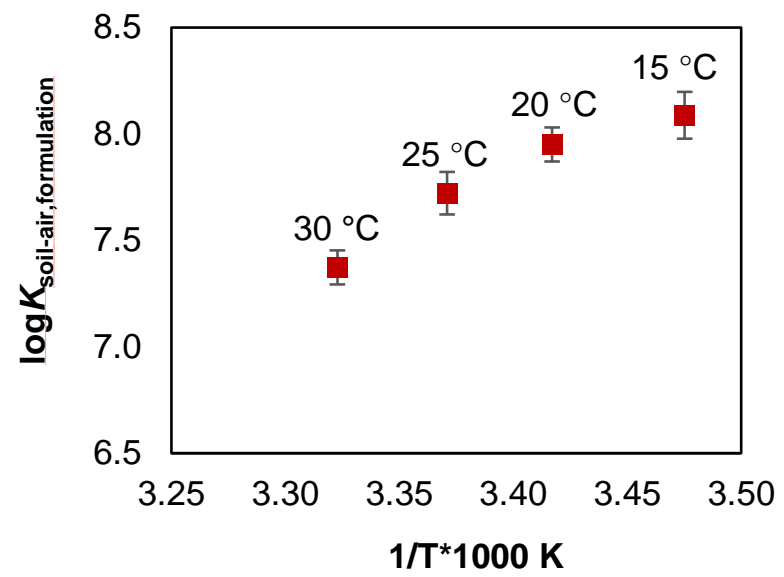

Figure 3. Effect of temperature on $\log K_{\text {soil-air,formulation values of chlorpyrifos }}$ at $\mathrm{RH}$ of $75 \%$. Error bars represent one standard deviation $(n=3)$.

294 AI in a protective matrix. However, the relevance of results obtained with glass slides in relation 295 to pesticide partitioning to soil is not currently known.

296 Influence of Temperature on Soil-air Partitioning with and without Formulation Adjuvants.

297 Chlorpyrifos $K_{\text {soil-air,formulation values decreased by approximately half an order of magnitude }}$ 298 with each $10{ }^{\circ} \mathrm{C}$ increase in temperature (Figure 3). While it is not surprising that temperature 299 affected $K_{\text {soil-air,formulation values, }}{ }^{27,}$ 33, 34 Davie-Martin et al. reported a much larger temperature 300 effect on chlorpyrifos for the same temperature range using pure AI bound to soil in a fugacity 301 meter with the Column Design (Figure 4). ${ }^{13}$ In that study, $K_{\text {soil-air,AI values decreased by }}$ 302 approximately one order of magnitude with each $10{ }^{\circ} \mathrm{C}$ increase in temperature. The internal 303 energy for the phase transfer of the AI from the soil phase to the gas phase $\left(\Delta_{\text {soil-air }} U\right)$ was calculated 304 for chlorpyrifos in the presence and absence of formulation adjuvants using Eq. 1 and the slopes 305 shown in Figure 4. 


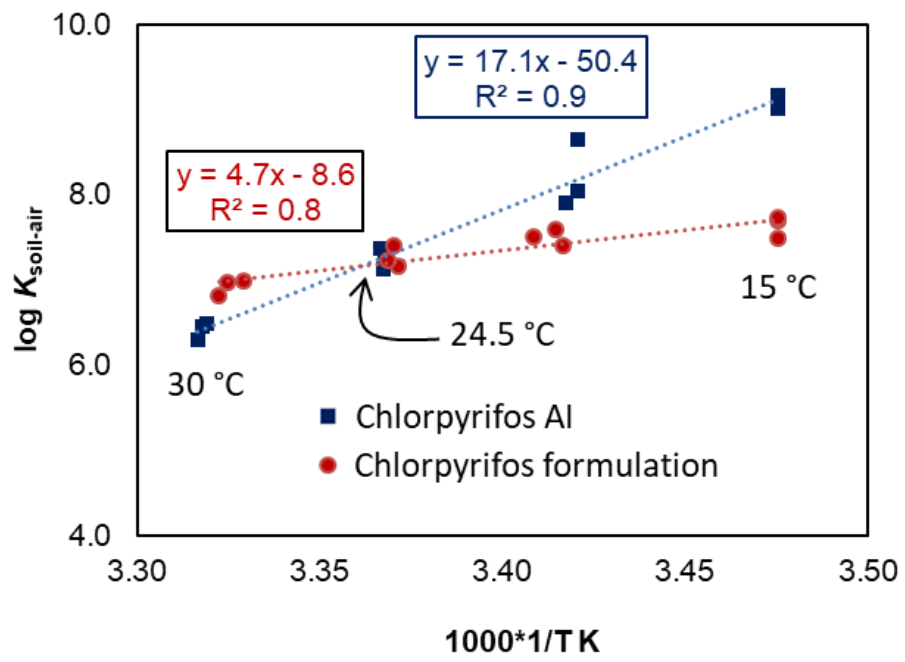

Figure 4. Comparison of temperature effects on $K_{\text {soil-air values for chlorpyrifos when }}$ applied in the absence (data from Davie-Martin et $a{ }^{1}{ }^{1}$ and presence of formulation adjuvants (data from this study).

307 where $A$ is the slope, $R$ is the ideal gas constant $\left(0.008314 \mathrm{~kJ} \mathrm{~mol}^{-1} \mathrm{~K}\right)$ and 2.303 is the 308 multiplication factor to convert from the natural logarithm to the common logarithm. The $309 \Delta_{\text {soil-air }} U_{\mathrm{AI}}$ and a $\Delta_{\text {soil-air }} U_{\text {formulation }}$ values were $328 \mathrm{~kJ} \mathrm{~mol}^{-1}$ and $90 \mathrm{~kJ} \mathrm{~mol}^{-1}$, respectively $($ Figure 2), indicating that $\sim 3.5$ times less energy was required for the phase transfer when the formulation 311 adjuvants were present, supporting our hypothesis about formulation adjuvants disrupting or
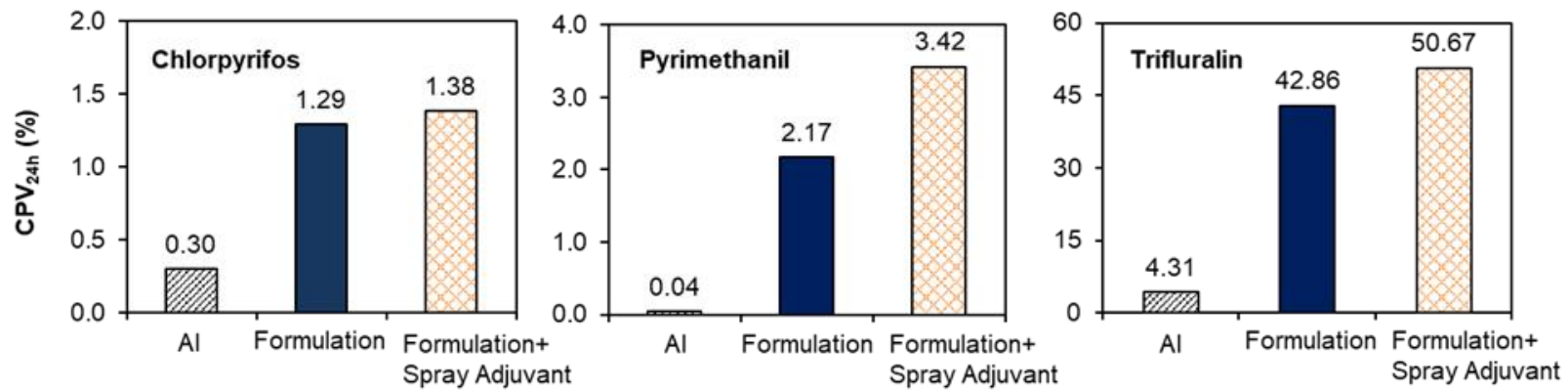

Figure 5. Comparison of predicted pesticide volatilization rates, obtained with the PLoVo model and expressed as CPV $24 \mathrm{~h}$, when applied in the absence of adjuvants, in the formulation, and in the formulation with an additional spray adjuvant. $K_{\text {soil-air }}$ input values used in the PLoVo were measured in the laboratory at $\sim 25{ }^{\circ} \mathrm{C}$ and $\mathbf{7 5 \%}$ relative humidity. 


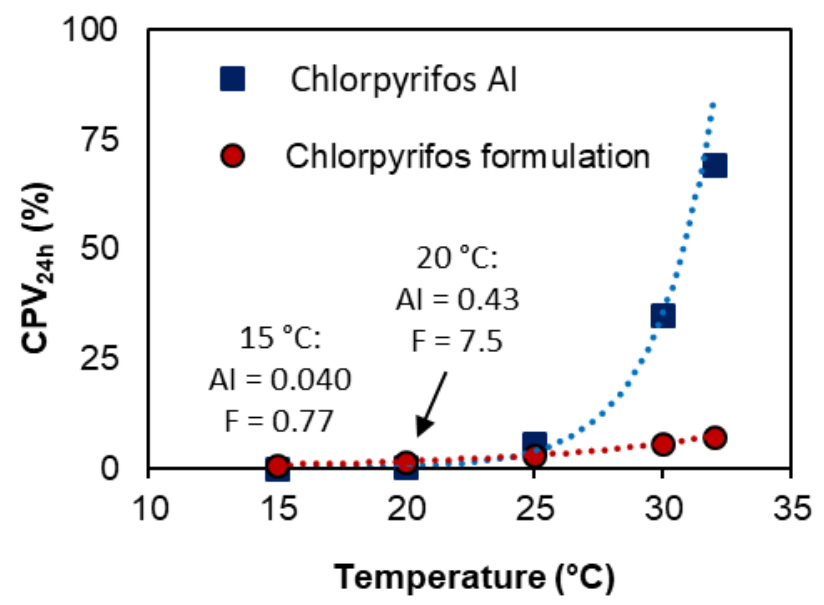

\section{Figure 6. Comparison of predicted $\mathrm{CPV}_{24 \mathrm{~h}}$ values, obtained with the PLoVo model, for chlorpyrifos applied in the absence of adjuvants (AI) and in the formulation $(F)$, at various temperatures.}

312 weakening the intermolecular attraction bonds between pesticides and soil. Future research should

313 focus on measuring $\Delta_{\text {soil-air }} U$ from additional soil types and with other RHs; however, Meijer et al.

314 showed that $\Delta_{\text {soil-air }} U$ values of organochlorines did not vary significantly when using three soils

315 (Hawaii, soybean, and muck soil) with different soil organic carbon contents. ${ }^{27}$

316 Another interesting feature of Figure 4 is that the two lines intersected at $24.5{ }^{\circ} \mathrm{C}$. This

317 means that the formulation adjuvants had a relatively small effect on chlorpyrifos interactions with

318 soil at around this temperature; but that chlorpyrifos interactions with soil were weaker in the

319 presence of formulation adjuvants at lower temperatures and stronger in the presence of

320 formulation adjuvants at higher temperatures. While this data suggests that the effects of adjuvants

321 on pesticide interactions with soil may be much more complicated and difficult to predict that

322 suspected, Figure 4 led us to hypothesize that the proposed mechanism shown in Figure 2 was

323 relevant at relatively low temperatures but that at relatively high temperatures, the interactions in

324 the more complicated chlorpyrifos-adjuvant-soil system were more robust and not as effected by

325 temperature. 
Due to the substantial amount of time required for each fugacity meter experiment, we did

327

not evaluate the effects of temperature on the partitioning behaviors of trifluralin and pyrimethanil in the presence and absence of adjuvants. Considering the important implications associated with the temperature affects we observed for chlorpyrifos, more work in this area is certainly warranted.

\section{Effect of Formulation on Predicted Volatilization Losses.}

Figure 5 compares the predicted pesticide $\mathrm{CPV}_{24 \mathrm{~h}}$ values from the model non-planted agricultural field when using the $K_{\text {soil-air,AI }}, K_{\text {soil-air,formulation, and } K_{\text {soil-air,formulation+spray adjuvant }} \text { values }}$ we measured at $\sim 24^{\circ} \mathrm{C}$ and $75 \% \mathrm{RH}$ as input parameters in the PLoVo model. For chlorpyrifos, the $\mathrm{CPV}_{24 \mathrm{~h}}$ was around four times higher in the presence of formulation adjuvants than without. For trifluralin and pyrimethanil, the $\mathrm{CPV}_{24 \mathrm{~h}}$ values were around ten times higher in the presence of formulation adjuvants than without. For all three pesticides, the addition of the spray adjuvant to the formulation had a minimal effect on $\mathrm{CPV}_{24 \mathrm{~h}}$ values.

Figure 6 shows the predicted $\mathrm{CPV}_{24 \mathrm{~h}}$ values for chlorpyrifos from the model non-planted

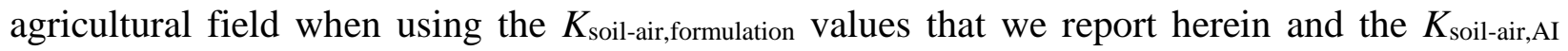
values reported previously ${ }^{1}$ as input parameters in the PLoVo model. As expected from the trends

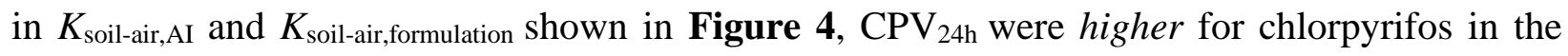
absence of formulation adjuvants at the relatively low temperatures but significantly lower for chlorpyrifos in the presence of adjuvants at the relatively high temperatures. Due to the exponential relationship between temperature and volatilization, $\mathrm{CPV}_{24 \mathrm{~h}}$ values were approximately twice as high for chlorpyrifos in the absence of formulation adjuvants at $\sim 24{ }^{\circ} \mathrm{C}$ but $\sim 10$ times higher at $\sim 32^{\circ} \mathrm{C}$. This temperature effect could be responsible for some previously observed inconsistencies in the effects of adjuvants on pesticide volatilization in the literature. 
The average volatilization losses of chlorpyrifos, pyrimethanil and trifluralin after applications in various lab and field studies, as reported here and in the literature, are compiled in Tables S15-17. Despite a variety of soil types and experimental conditions being used, it is clear that pesticide volatilization from glass surfaces was substantially higher than from soil for all three pesticides. This is not surprising considering the potential for much stronger and more complex interactions between pesticides and soil relative to pesticides and glass surfaces.

\section{RECOMMENDATIONS}

The results from this study provide information about the effects of adjuvants on the soil-air partitioning for three specific pesticides, formulations, and adjuvants. However, more research is needed to gain a broader understanding of these effects, for example, with other pesticides, adjuvants, soil types, relative humidities, and on plant surfaces. Improved access to detailed chemical composition data in pesticide formulations would facilitate better understanding of chemical interactions and more systematic investigations into adjuvant effects.

\section{SUPPORTING INFORMATION}

Additional details about pesticide formulations, previous studies, methods and materials, quality control, and results.

\section{ACKNOWLEDGMENTS}

We thank the University of Otago for financial support (Postgraduate Scholarship and Publishing Bursary for Supta Das), Tom Orchiston (AgResearch, Invermay) for providing the soil, Cleo Davie-Martin (University of Copenhagen) and Garth Tyrell (University of Otago) for assistance with the fugacity meter set-up, and William Doucette (Utah State University) and Andrew Hewitt (University of Queensland) for helpful reviews of this work. 


\section{REFERENCES}

377 1. Rüdel, H., Volatilisation of pesticides from soil and plant surfaces. Chemosphere, 1997, 35, 143-152.

2. Houbraken, M., Senaeve, D., Dávila, E.L., Habimana, V., De Cauwer, B., and Spanoghe, P., Formulation approaches to reduce post-application pesticide volatilisation from glass surfaces. Science of the Total Environment, 2018, 633, 728-737.

3. Bedos, C., Cellier, P., Calvet, R., Barriuso, E., and Gabrielle, B., Mass transfer of pesticides into the atmosphere by volatilization from soils and plants: Overview. Agronomie, 2002, 22, 21-33.

4. Leistra, M., Smelt, J.H., Hilbrand Weststrate, J., Van Den Berg, F., and Aalderink, R., Volatilization of the pesticides chlorpyrifos and fenpropimorph from a potato crop. Environmental Science and Technology, 2006, 40, 96-102.

5. Xiao, H., Kang, S., Zhang, Q., Han, W., Loewen, M., Wong, F., Hung, H., Lei, Y.D., and Wania, F., Transport of semivolatile organic compounds to the Tibetan Plateau: Monthly resolved air concentrations at Nam Co. Journal of Geophysical Research D: Atmospheres, 2010, 115, Article D16310.

6. Hageman, K.J., Hafner, W.D., Campbell, D.H., Jaffe, D.A., Landers, D.H., and Simonich, S.L.M., Variability in pesticide deposition and source contributions to snowpack in western U.S. national parks. Environmental Science and Technology, 2010, 44, 4452-4458.

7. van den Berg, F., Jacobs, C.M.J., Butler Ellis, M.C., Spanoghe, P., Doan Ngoc, K., and Fragkoulis, G., Modelling exposure of workers, residents and bystanders to vapour of plant protection products after application to crops. Science of the Total Environment, 2016, 573, 1010-1020.

8. Zivan, O., Bohbot-Raviv, Y., and Dubowski, Y., Primary and secondary pesticide drift profiles from a peach orchard. Chemosphere, 2017, 177, 303-310.

9. Urlacher, E., Monchanin, C., Rivière, C., Richard, F.J., Lombardi, C., Michelsen-Heath, S., Hageman, K.J., and Mercer, A.R., Measurements of Chlorpyrifos Levels in Forager Bees and Comparison with Levels that Disrupt Honey Bee Odor-Mediated Learning Under Laboratory Conditions. Journal of Chemical Ecology, 2016, 42, 127-138.

10. Jones, G.T., Norsworthy, J.K., Barber, T., Gbur, E., and Kruger, G.R., Off-target Movement of DGA and BAPMA Dicamba to Sensitive Soybean. Weed Technology, 2019, $33,51-65$.

11. Vos, J.G., Dybing, E., Greim, H.A., Ladefoged, O., Lambré, C., Tarazona, J.V., Brandt, I., and Vethaak, A.D., Health effects of endocrine-disrupting chemicals on wildlife, with special reference to the European situation. Critical Reviews in Toxicology, 2000, 30, 71133.

12. Freemark, K. and Boutin, C., Impacts of agricultural herbicide use on terrestrial wildlife in temperate landscapes: A review with special reference to North America. Agriculture, Ecosystems and Environment, 1995, 52, 67-91.

13. Davie-Martin, C.L., Hageman, K.J., Chin, Y.P., Rougé, V., and Fujita, Y., Influence of Temperature, Relative Humidity, and Soil Properties on the Soil-Air Partitioning of Semivolatile Pesticides: Laboratory Measurements and Predictive Models. Environmental Science and Technology, 2015, 49, 10431-10439.

14. Taylor, M.R., Lyons, S.M., Davie-Martin, C.L., Geoghegan, T.S., and Hageman, K.J., Understanding Trends in Pesticide Volatilization from Agricultural Fields using the 
Pesticide Loss via Volatilization (PLoVo) Model. Environmental Science \& Technology, 2019, 54, 2202-2209.

15. Hock, W. Spray Adjuvants. 2016 Accessed: October 2019]; Available from: https://extension.psu.edu/spray-adjuvants.

16. Holoman Jr, S. and Seymour, K.G. Laboratory Measurement of Pesticide Vapor Losses. in ASTM Special Technical Publication. 1983.

17. Stevens, P.J.G. and Bukovac, M.J., Studies on octylphenoxy surfactants. Part 1: Effects of oxyethylene content on properties of potential relevance to foliar absorption. Pesticide Science, 1987, 20, 19-35.

18. Houbraken, M., Senaeve, D., Fevery, D., and Spanoghe, P., Influence of adjuvants on the dissipation of fenpropimorph, pyrimethanil, chlorpyrifos and lindane on the solid/gas interface. Chemosphere, 2015, 138, 357-363.

19. Dailey, O.D., Volatilization of Alachlor from Polymeric Formulations. Journal of Agricultural and Food Chemistry, 2004, 52, 6742-6746.

20. Davie-Martin, C.L., Hageman, K.J., and Chin, Y.P., An improved screening tool for predicting volatilization of pesticides applied to soils. Environmental Science and Technology, 2013, 47, 868-876.

21. Orion AGRISCIENCE. Synoil TM. Accessed: October 2016]; Available from: http://www.orionagriscience.co.nz/adjuvants/Synoil.

22. Horstmann, M. and McLachlan, M.S., Initial development of a solid-phase fugacity meter for semivolatile organic compounds. Environmental Science and Technology, 1992, 26, 1643-1649.

23. Davie-Martin, C.L., Hageman, K.J., Chin, Y.-P., Rougé, V., and Fujita, Y., Influence of temperature, relative humidity, and soil properties on the soil-air partitioning of semivolatile pesticides: Laboratory measurements and predictive models. Environmental Science and Technology, 2015, 49, 10431-10439.

24. Goss, K.U., Buschmann, J., and Schwarzenbach, R.P., Adsorption of organic vapors to airdry soils: Model predictions and experimental validation. Environmental Science and Technology, 2004, 38, 3667-3673.

25. Cousins, I.T., McLachlan, M.S., and Jones, K.C., Lack of an aging effect on the soil-air partitioning of polychlorinated biphenyls. Environmental Science and Technology, 1998, 32, 2734-2740.

26. Sharer, M., Park, J.-H., Voice, T.C., and Boyd, S.A., Aging effects on the sorptiondesorption characteristics of anthropogenic organic compounds in soil. Journal of Environmental Quality, 2003, 32, 1385-1392.

27. Meijer, S.N., Shoeib, M., Jones, K.C., and Harner, T., Air-soil exchange of organochlorine pesticides in agricultural soils. 2. Laboratory measurements of the soil-air partition coefficient. Environmental Science and Technology, 2003, 37, 1300-1305.

28. US EPA, Estimation Programs Interface Suite ${ }^{\mathrm{TM}}$ for Microsoft ${ }^{\circledR}$ Windows, v 4.11. 2020, United States Environmental Protection Agency,: Washington, DC, USA.

29. Wong, F. and Bidleman, T.F., Aging of organochlorine pesticides and polychlorinated biphenyls in muck soil: Volatilization, bioaccessibility, and degradation. Environmental Science and Technology, 2011, 45, 958-963.

30. Kearney, P.C., Shelton, D.R., and Koskinen, W.C., Soil Chemistry of Pesticides, in KirkOthmer Encyclopedia of Chemical Technology. 2000. 
466 31. Pose-Juan, E., Rial-Otero, R., Paradelo, M., and López-Periago, J.E., Influence of the adjuvants in a commercial formulation of the fungicide "Switch" on the adsorption of their active ingredients: Cyprodinil and fludioxonil, on soils devoted to vineyard. Journal of Hazardous Materials, 2011, 193, 288-295.

32. Katagi, T., Surfactant effects on environmental behavior of pesticides, in Reviews of Environmental Contamination and Toxicology. 2008. p. 71-177.

33. Cousins, I.T., Beck, A.J., and Jones, K.C., A review of the processes involved in the exchange of semi-volatile organic compounds (SVOC) across the air-soil interface. Science of the Total Environment, 1999, 228, 5-24.

34. He, X., Chen, S., Quan, X., Zhao, Y., and Zhao, H., Temperature-dependence of soil/air partition coefficients for selected polycyclic aromatic hydrocarbons and organochlorine pesticides over a temperature range of -30 to $+30{ }^{\circ} \mathrm{C}$. Chemosphere, 2009, 76, 465-471.

478

479

480

TABLE of CONTENTS ART

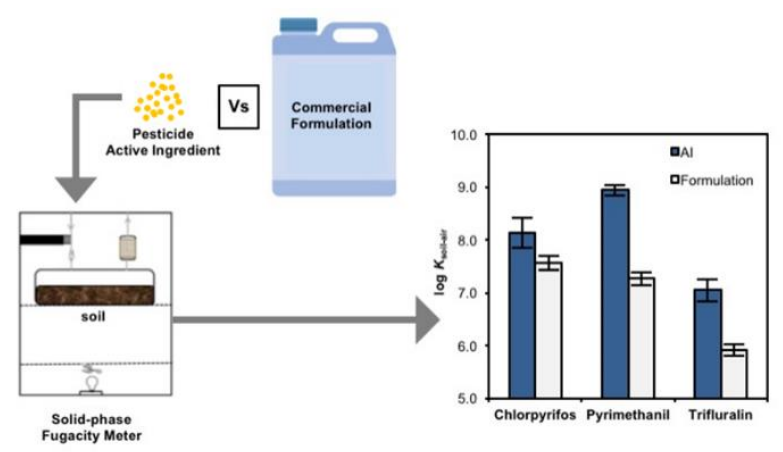

